\title{
Blockade of epinephrine-induced decrement in activity by scopolamine'
}

\author{
Peter G. MANTO, JR. \\ RUTGERS, THE STATE UNIVERSITY
}

Injection of epinephrine reduced motor activity. This effect is prevented by scopolamine, but not by methyl scopolamine. The reduction in motor activity may thus be due to a centrally mediated "rebound" of parasympathetic activity.

Behavioral studies of the effects of injected epinephrine (E) have indicated that the drug reduced motor activity (e.g., Kosman \& Gerard, 1955; Moyer \& Bunnell, 1958; Leshner \& Stewart, 1966). One possible basis for this effect is that the $\mathrm{E}$ may induce a "rebound" of parasympathetic activity; i.e., an induced state of parasympathetic dominance in which the organism's capacity to produce physical effort is diminished. Among the specific effects of this state is the loss of muscle tone (Gloor, 1954). Gellhorn (1957) has suggested that parasympathetic dominance may be induced when sympathetic arousal is intense. He has pointed out that this regulation seems to limit excessive degrees of sympathetic activation. Thus, E could lead to parasympathetic "rebound" and, thereby, reduced motor activity. Similarly, Brush (1964) has suggested that poor avoidance behavior following fear conditioning may be due to a parasympathetic overreaction. This, too, could be a result of high levels of $E$ induced by fear conditioning.

In the experiments reported here, an attempt was made to block the E-induced decrement in motor activity by pre-treating rats with scopolamine. Scopolamine is a drug that reduces the muscarinic, parasympathetic actions of the synaptic transmitter, acetylcholine $(\mathrm{ACH})$ in the peripheral nervous system and, evidently, in the brain (Goodman \& Gilman, 1955).

Methyl scopolamine was also studied. Methyl scopolamine is a drug that has about the same peripheral potency as scopolamine but, because it does not readily pass the blood brain barrier, has much less central potency (see Carlton, 1963, for references).

It was reasoned that the use of these drugs would block parasympathetic activity that might be induced by $\mathrm{E}$ and, thus, block the reduction of motor activity. In addition, by comparing the relative effectiveness of scopolamine and methyl scopolamine, the roles of central and peripheral processes in parasympathetic "rebound" could be evaluated.

\section{EXPERIMENT 1}

\section{Method}

The Ss were 11 male Sprague-Dawley rats that weighed 300-350 $\mathrm{gm}$ at the start of the experiment. They had previously been used in a magnitude of reward study involving sucrose concentrations. The apparatus consisted of four Gerbrands student demonstration boxes with levers and food cups removed. Ss' activity was recorded by means of low-amp contact relays wired to the grid floors of the boxes. The boxes were housed in a partitioned, sound attenuated chamber. Ss were maintained on ad lib food and water throughout the experiment.

At the start of the experiment each of the Ss was subjected to one of four experimental treatments, each involving two injections separated by 5 min.: (1) $1.0 \mathrm{cc} / \mathrm{kg}$ physiological saline followed by a second saline injection (treatment $\mathrm{S}-\mathrm{S}$ ); (2) saline followed by $.30 \mathrm{mg} / \mathrm{kg}$ epinephrine hydrochloride (S-E); (3) .50 $\mathrm{mg} / \mathrm{kg}$ scopolamine hydrobromide followed by $.30 \mathrm{mg} /$ $\mathrm{kg}$ epinephrine hydrochloride (Sc-E); and (4) $.50 \mathrm{mg} / \mathrm{kg}$ scopolamine hydrobromide followed by saline (Sc-S). All injections were administered intraperitoneally; all doses have been given in terms of the salts. Ten min. after the second injection, the Ss were placed in the experimental boxes and spontaneous activity was recorded for a 2-hr. period. Ss were then returned to their home cages. Subsequently, each $S$ received each of the four treatments, counterbalanced for order, and four activity recording sessions. The inter-treatment interval was four days.

Results

Spontaneous activity, under each of the experimental treatments, was compared on a within-Ss basis. Between-treatments differences were assessed by means

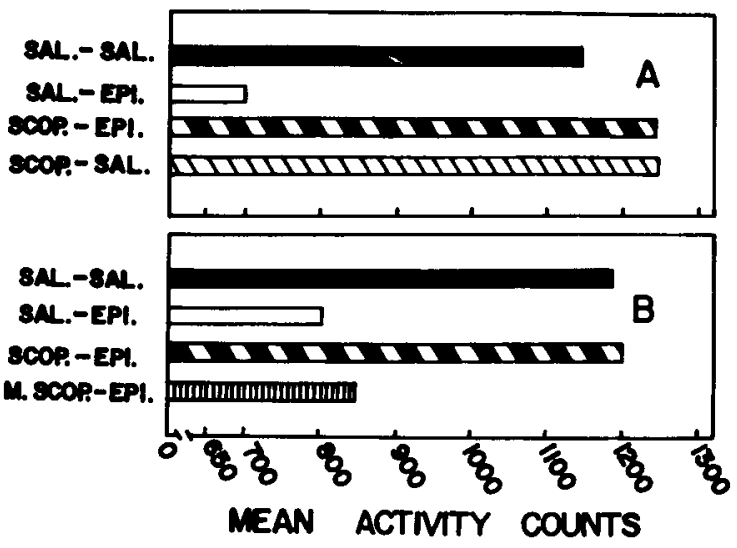

Fig. 1. Within-subjects mean activity as a function of preceding drug treatment. 
of the Wilcoxon matched pairs signed-ranks test (Siegel, 1956). It was found that treatment S-E led to decreased activity relative to the control treatment, $S-S(p<.02$, two-tailed). Thus, injection of $E$ produced a reliable decrement in activity. In contrast, treatment Sc-E did not differ from treatment S-S, but did lead to greater activity relative to treatment $S-E$ $(p<.05)$. Injection of scopolamine evidently blocked the E-induced reduction in activity. However, treatment Sc-S did not differ from treatment S-S. Therefore, the blockade of E-induced reduction of activity by scopolamine does not appear to be attributable to a direct stimulatory effect of the drug at this dose. These data are shown in Fig. 1-A.

\section{EXPERIMENT 2}

\section{Method}

The Ss were 11 male Sprague-Dawley rats that weighed 260-320 gm at the start of the experiment. The Ss had previously been used in a choice study involving food reinforcement. The apparatus was identical to that used in Experiment 1. The procedure was the same as in Experiment 1 except that treatment Sc-S was replaced by treatment MSc-E; i.e., $.50 \mathrm{mg} / \mathrm{kg}$ scopolamine methylbromide (methyl scopolamine) followed by $.30 \mathrm{mg} / \mathrm{kg}$ epinephrine hydrochloride $5 \mathrm{~min}$. later.

\section{Results}

As was the case in Experiment 1, treatment $S-E$ led to decreased activity relative to treatment $S-S$ $(p<.02)$. Similarly, treatment Sc-E did not differ from treatment $S-S$, but did lead to increased activity relative to treatment $S-E(p<.05)$. Again, E produced a decrement in activity that was blocked by a previous injection of scopolamine. Treatment MSc-E, on the other hand, led to decreased activity relative to treatment $S-S(p<.05)$ and did not differ from treatment S-E. Methyl scopolamine, unlike scopolamine, was not effective in blocking $E$-induced reduction in activity. These data are shown in Fig. 1-B.

\section{Discussion}

Injection of $\mathrm{E}$ leads to a decrease in motor activity. Animals that are pre-treated with the centrally active, parasympathetic antagonist scopolamine, are not as depressed by $\mathrm{E}$. In fact, with this dose of scopolamine they showed activity levels comparable to animals that had not receieved an $E$ injection. Scopolamine was not, however, effective in increasing the activity of otherwise untreated animals. This effect of scopolamine cannot, therefore, be attributed to a simple additive increase in spontaneous activity. Because the E-induced decrease in activity is blocked by the introduction of a drug that blocks parasympathetic activity, it may reasonably be inferred that injection of $\mathrm{E}$ induces parasympathetic excitation that tends to inhibit activity.

The basic findings of Experiment 1 were replicated in Experiment 2. In addition, it was noted that an equimolar dose of methyl scopolamine, an anticholinergic that has equivalent potency to scopolamine peripherally, but which passes the blood brain barrier very poorly, did not block the E-induced decrease in activity. The condition of parasympathetic dominance that seems to occur following intense sympathetic activity can, therefore, be most reasonably attributed to a process in the brain, rather than the peripheral nervous system.

\section{References}

Brush, F. R. Avoidance learning as a function of time after fear conditioning and unsignalled shock. Psychon. Sci., 1964, 1, 405-406.

Carlton, P. L. Cholinergic mechanisms in the control of behavior by the brain. Psychol. Rev., 1963, 70, 19-39.

Gellhom, E. Autonomic imbalance and the hypothalamus. Minneapolis: University of Minnesota Press, 1957.

Gloor, P. Autonomic functions of the diencephalon. Arch. Neurol. Psychiat., Chicago, 1954, 71, 773-790.

Goodman, L. S., \& Gilman, A. The pharmacological basis of therapeutics. New York: Macmillan, 1955.

Kosman, M. E., \& Gerard, R. W. The effect of adrenalin on a conditioned avoidance response. J. comp. physiol. Psychol., 1955 , 48,506 .

Leshner, A. I., \& Stewart, C. N. The effect of epinephrine on extinction of an avoidance response. Psychon. Sci., 1966, 5, $89-90$.

Moyer, K. E., \& Bunnell, B. N. Effect of injected adrenalin on an avoidance response in the rat. J. genet. Psychol., 1958, 92, 247-251.

Siegel, S. Nonparametric statistics for the behavioral sciences. New York: McGraw-Hill, 1956.

\section{Note}

1. Research supported by PHS grant MH-08585 to Peter L. Cariton and by NIMH fellowship 1-F1-MH-31, 627-01 (PS) to the author. 